\title{
Pedestrian Tow Truck Operator Struck and Killed by Drunk Driver While Rendering Assistance on Highway Roadside
}

\section{CASE SUMMARY}

On Thursday night, July 3, 2014, a 35-year-old tow truck driver and his 31-year-old male driver trainee arrived on the scene to assist a 1998 Volkswagen Beetle driver who needed his vehicle to be towed. The tow truck driver parked his towing unit in front of the Volkswagen Beetle on the eastbound shoulder of the roadway. The victim was operating the lift controls on the traffic facing side of the tow truck, when a 2002 Toyota Corolla struck the open driver's side door of the Volkswagen, then struck the tow truck driver and the side mirror on the tow truck. The Toyota Corolla driver continued driving, while the Volkswagen driver called Emergency Medical Services. EMS arrived within four minutes and attempted to resuscitate the victim. The time of death was called at 11:54 pm at the scene.

\section{Recommendations for prevention:}

- When tow vehicles are equipped with dual winch controls, drivers should operate controls from the non-traffic facing side of the truck.

- Towing companies should consider utilizing portable emergency warning devices.

- Highway incident managers should always wear ANSI compliant high visibility work apparel appropriate for the time of day or night while responding to roadside assistance calls.

- Tow truck operators should consider National Traffic Incident Management Responder Training, regardless of company size.

- There should be increased public awareness of the "Move Over Law" in Kentucky. 


\section{EMPLOYER}

The victim was the self-employed owner/operator of the towing company since 2004. He was the sole business proprietor who employed several workers. The tow truck driver had a driver trainee with him when the incident occurred. It is unclear what safety training the victim had completed before the fatal incident.

\section{SAFETY AND TRAINING PROGRAMS}

It is unknown if the victim completed formal safety training, but the victim provided informal “on-the-job” training for his newly-hired employees.

\section{VICTIM}

The victim was a 35-year-old father of four with some high school education, but had not received a diploma. On the evening of the incident, he was wearing navy blue pants and a blue tee-shirt that was not considered to be high visibility clothing.

\section{INCIDENT SCENE}
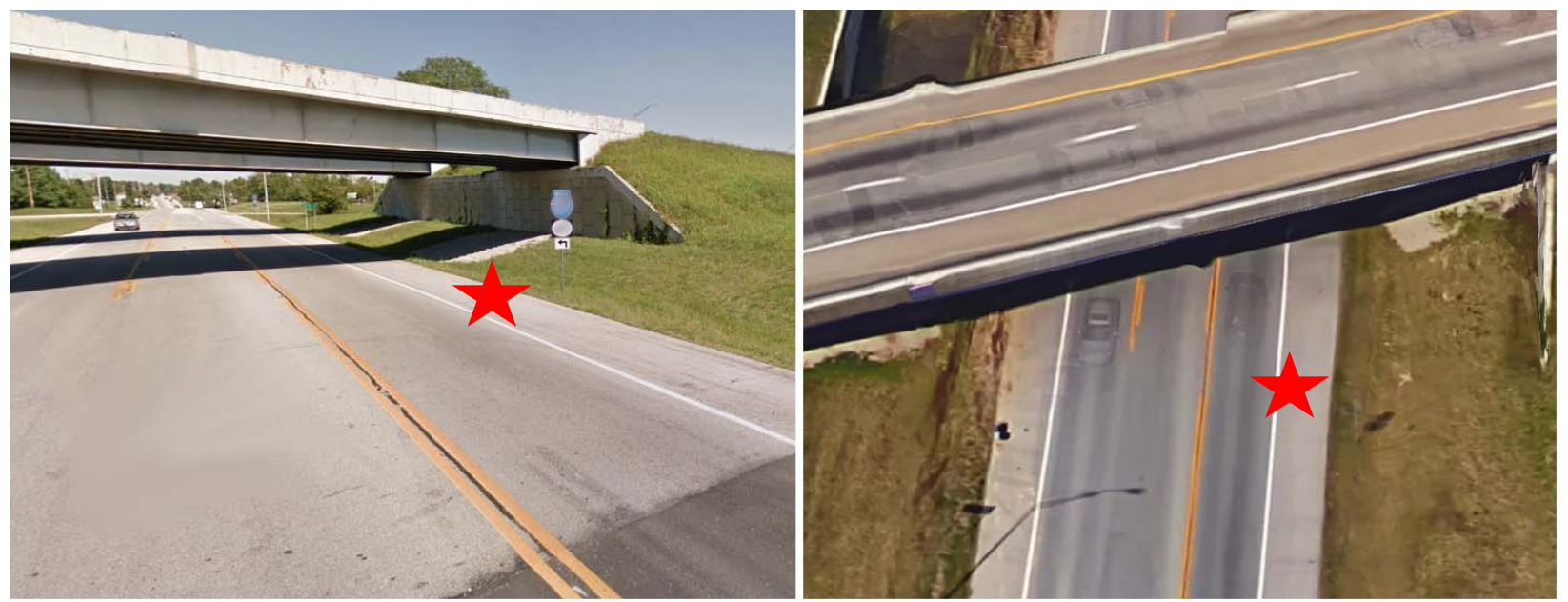

Figure 2. Ground and aerial view of the incident scene. The red star denotes approximately where the driver was standing upon being struck.

The incident scene was the eastbound lane of a two-lane state highway with a central turning lane dividing the two sides. Located just under a 4-lane highway overpass, the road was partially illuminated with streetlights. The roadway was straight, level and dry. The tow truck was parked 2-3 feet from the driving lane. The victim was on the right shoulder of the highway near the lift controls on the left-hand side of his truck. Directly behind the tow truck on the shoulder was a stalled Volkswagen Beetle in need of roadside assistance. 


\section{EQUIPMENT}
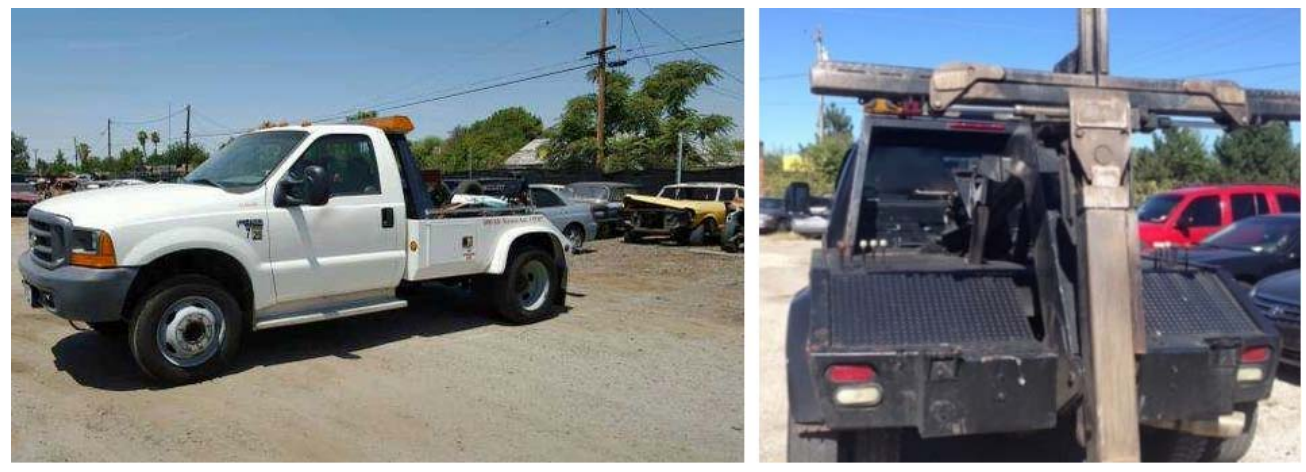

Figure 3. Stock

images of a Ford F450 tow truck (this is not the exact unit involved in the incident).

The tow truck was a 1999 Ford F450 wheel lift tow truck (2 axle, 6 tires). The truck was equipped with dual winch controls on both sides of the truck for towing purposes. It is unknown if both winch controls were operational. The tow truck was equipped with a light bar with flashing LED warning lights and working lights.

\section{WEATHER}

At the time of the incident, the temperature was approximately $70^{\circ} \mathrm{F}$ and the skies were partly to mostly cloudy; wind speeds registered at 4-5 miles per hour and were primarily coming from the north-northeast direction. Humidity registered at $63 \%$. There was no precipitation and the roadway was dry. Weather was not considered a contributing factor to the incident.

\section{INVESTIGATION}

The incident took place on a cloudy, dark summer night on Thursday, July 3, 2014. A 35-yearold tow truck driver and father of four was driving to his fiancé's home when a customer called to request roadside assistance. The tow truck driver told the caller he would be there in five to ten minutes, then called his fiancé to let her know that he was responding to his last call of the evening and would be home afterwards. The call was made shortly after 11:00 pm.

The tow truck driver and his 31-year-old male driver trainee arrived at the scene, where they found a 1998 Volkswagen Beetle stalled in the right-hand emergency lane of a 2-lane highway. The vehicle, facing east, was located approximately 18 feet away from a 4-lane highway overpass. A single streetlight illuminated the opposite side of the roadway approximately 73 feet away; the only other external light sources were the warning flashing lights and working lights on the tow truck light bar. The tow truck driver positioned his truck on the shoulder of the road in front of the Volkswagen. Wearing low-to-no visibility reflective clothing, the tow truck driver exited his truck to speak with the driver of the Volkswagen. After a brief discussion, the tow truck driver agreed to tow the Volkswagen to the dealership and drop the driver off at his home. 
The driver trainee stood by the passenger side of the tow truck in a grassy area observing the tow truck driver. The tow truck driver operated the traffic-side winch controls of his tow truck, while the Volkswagen driver remained in his seat. As the tow truck driver adjusted the winch controls, a 2002 Toyota Corolla veered onto the right shoulder and struck the open driver's side door of the Volkswagen, then struck the victim and the driver's side mirror of the tow truck (see figure 4). The Toyota came to a brief rest on the eastbound shoulder in front of the tow truck, then fled the scene without rendering assistance to the victim.

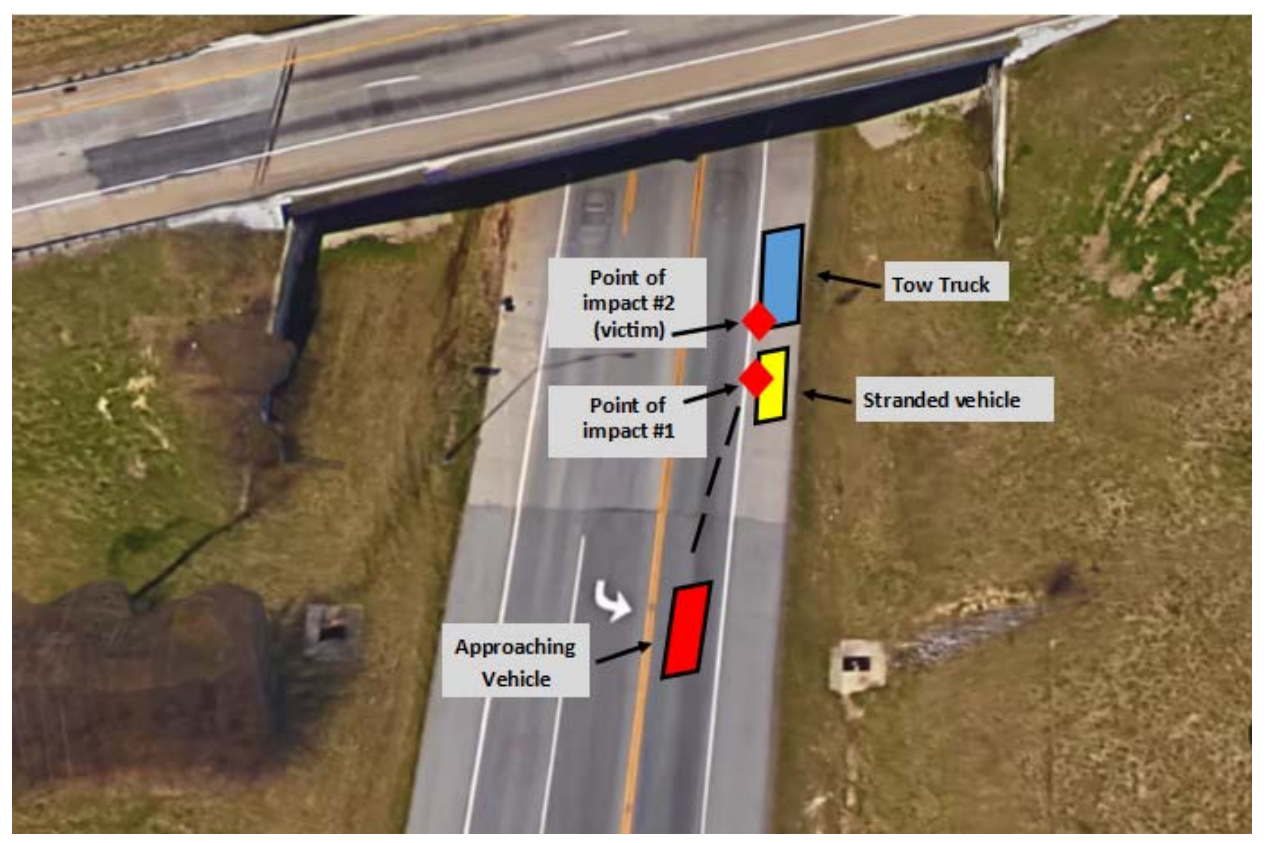

Figure 4. Trajectory of the crash and locations of vehicles and victim.

The Volkswagen owner placed a call at 11:35 pm to emergency medical services, then assisted the tow truck driver until EMS arrived after four minutes and tried to resuscitate the victim. The tow truck driver was pronounced dead at 11:54 pm at the scene as a result of multiple blunt force injuries, including skull and vertebra fractures. The driver trainee and the Volkswagen driver were not injured.

Less than a half mile away from the scene, city police officers noticed a damaged 2002 Toyota Corolla with a shattered windshield and pulled the driver over. A breathalyzer test was administered and the driver was found to be driving under the influence with a blood alcohol level of 0.17 percent, twice the legal limit. The driver was charged with murder, leaving the scene of an accident, and drunk driving.

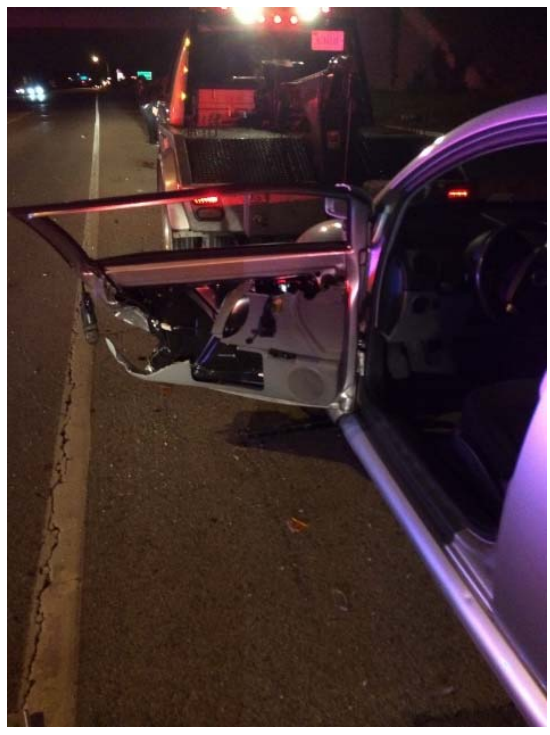

Figure 5. Volkswagen door following initial impact. 


\section{CAUSE OF DEATH}

The cause of death was blunt force injuries sustained in a motor vehicle vs. pedestrian collision. The main contributing injuries were skull and vertebra trauma.

\section{CONTRIBUTING FACTORS}

Often, occupational fatalities and injuries are caused by one or more contributing factor. The investigation identified the following factors that contributed to the tow truck driver's death:

- Use of winch controls located on the traffic side

- No reflective garments worn

- Dark conditions

- Lack of safety training

- Driver under the influence

\section{RECOMMENDATIONS AND DISCUSSIONS}

Recommendation No. 1: When tow vehicles are equipped with dual winch controls, drivers should operate controls from the non-traffic facing side of the truck.

This particular tow truck was equipped with dual winch controls on both the right and left sides of the truck. By utilizing the passenger side of the tow truck, the tow truck driver would have been better protected from oncoming traffic. Some tow truck companies secure the disabled vehicle on the non-traffic side until they can get to a safe location to secure the other side.

Recommendation No. 2: Towing companies should consider utilizing portable emergency warning devices.

The only warning device the tow truck driver used was the flashing light bar on top of the tow truck. Portable warning devices such as cones, flashing triangles, and road flares warn approaching motorists of a stopped emergency vehicle ahead and provide time for drivers to slow down and move over.

Recommendation No. 3: Highway incident managers should always wear ANSI compliant high visibility work apparel appropriate for the time of day or night while responding to roadside assistance calls ${ }^{1}$.

The American National Standard for High-Visibility Safety Apparel and Headwear (ANSI/ISEA 107-2010) is a standard established by the American National Standards Institute for protection of workers who are consistently exposed to low visibility hazards while performing their job, such as construction, maintenance, utility, emergency response workers etc. ANSI/ISEA standard 107 compliant garments and headwear are useful personal protective equipment (PPE) for workers exposed to struck-by hazards. 
ANSI/ISEA standard 107-2010 provides for a high degree of reflective material incorporated into garments, thus improving visibility and safety. There are three required classes of garments based on the work environment:

- Class 1 garments are intended for workers who are exposed to traffic that does not exceed $25 \mathrm{mph}$, such as safety vests for parking lot attendants, warehouse workers, and shopping cart retrievers.

- Class 2 garments are for workers who need higher visibility where traffic exceeds $25 \mathrm{mph}$ such as law enforcement, traffic, and school crossing guard personnel.

- Class 3 garments provide the highest level of visibility to workers in high risk environments that involve a wide range of weather conditions and traffic exceeding 50 mph. These garments cover the arms and legs, as well as the torso, and this is the required class for roadway construction personnel, highway incident managers, emergency responders, accident site investigators, etc.

The tow truck driver in this incident was not wearing reflective clothing. He was dressed in a blue tee-shirt and dark navy blue pants.

Recommendation No. 4: Tow truck operators should consider National Traffic Incident Management Responder Training, regardless of company size.

It is unknown if the tow truck driver completed Traffic Incident Management (TIM) training. Tow truck drivers should be knowledgeable of roadside assistance best practices and aware of potential hazards that are inherent to the job. TIM training offers both hands-on and web-based training on how to safely and properly execute a roadside response. Training topics include:

- TIM Fundamentals and Terminology

- Notification and Scene Size-Up

- Safe Vehicle Positioning

- Scene Safety

- Command Responsibilities

- Traffic Management

- Special Circumstances

- Clearance and Termination

Recommendation No. 5: There should be increased public awareness of the "Move Over Law" in Kentucky ${ }^{2,3}$.

Kentucky's Move Over Law was enacted in July 2000 and revised in June 2003. It is a law designed to protect police officers and other emergency workers stopped alongside the roadway. The law requires motorists to approach an emergency vehicle with caution when it is stopped 
with its lights flashing. Motorists must change lanes away from the emergency vehicle if they are traveling on a four-lane roadway and can do so safely. If drivers cannot change lanes safely or are traveling on a two-lane road, they must slow down while maintaining a safe speed so as not to impede other traffic.

\section{KEYWORDS}

Tow truck driver Reflective clothing Roadside assistance Night time towing Traffic incident management Highway incident management

\section{ADDITIONAL RESOURCES}

KY FACE Haz Alert: Traffic Incident Management Responders Struck and Killed by Oncoming Traffic. (http://www.mc.uky.edu/kiprc/projects/KOSHS/TIM_Responders_Struck_By_HazAlert.pdf)

KY FACE Case Report: Owner of Towing Company Dies When Struck by Box Truck. (http://www.mc.uky.edu/kiprc/projects/KOSHS/face/data/Reports/12KY035revised-MC-TB.pdf)

Towing and Recovery Association of America, Inc.

(http://traaonline.com/)

Move Over, America- Protecting law enforcement and emergency responders! National Safety Commission.

(http://www.moveoveramerica.com/)

\section{REFERENCES}

${ }^{1}$ Regulation and Policy: High Visibility Safety Apparel and Headwear Standard. Federal Highway Administration. Web. http://www.ops.fhwa.dot.gov/wz/resources/policy.htm

${ }^{2}$ KRS 189.930- Right-of-way to emergency vehicles - Blocking or following emergency vehicles - Driving over unprotected hoses of fire department. Kentucky Legislature. Web. http://www.Irc.ky.gov/Statutes/statute.aspx?id=6470

${ }^{3} \mathrm{KOHS}$, KSP launch 'Move Over' campaign to protect those who protect us. Message to drivers: Move Over. It's the Law. Kentucky Transportation Cabinet. Web. http://transportation.ky.gov/Highway-Safety/Documents/press_release_move-overcampaign_2015.pdf 


\section{PHOTO CREDIT}

Figures 2 and 4 photo credit goes to Google Maps. Figure 3 photo credit goes to autotrader.

\section{ACKNOWLEDGEMENTS}

The Kentucky FACE program would like to thank Roberts Heavy-Duty Towing and the State Highway Patrol for their assistance with this report.

\section{PROGRAM FUNDING}

The Kentucky Fatality Assessment \& Control Evaluation Program (FACE) is funded by grant 2U60OH008483-11 from the Centers for Disease Control and Prevention and the National Institute for Occupational Safety and Health.

Please take the time to complete our brief survey regarding this report:

(https://uky.az1.qualtrics.com/SE/?SID=SV_6Vxuhu4pgVUcv5P)

Electronic access to this full report can be found here:

(http://www.mc.uky.edu/kiprc/programs/face/files/14KY033.pdf)

\section{FACE on Social Media:}

https://www.facebook.com/Kentucky-FACE-Program-

$\underline{134135740092906 / \text { ?view_public for }=134135740092906}$

http://www.twitter.com/KYFACEProgram 
This case report was developed by the Kentucky Fatality Assessment and Control Evaluation (FACE) Program. Kentucky FACE is a NIOSH-funded occupational fatality surveillance program with a goal of preventing fatal work injuries by studying the worker, the work environment, and the role of management, engineering, and behavioral changes in preventing future injuries. The FACE Program is located within the Kentucky Injury Prevention and Research Center (KIPRC), part of the University of Kentucky's College of Public Health.

Email: kyfaceprogram@uky.edu | Telephone: 859-257-5839 333 Waller Avenue Suite 242, Lexington, KY 40504 